the dressing, however, and sponged away the coagulated blood, I found that the previous pressure, aided by exposure to the atmosphere and the application of cold sponging, stopped the bleeding immediately; and although I searched carefully over the surface of the wound, I did not succeed in finding the open vessel. It was not the axillary artery, as I had suspected, for it was still safe, but from the sitnation of the only gush of blood I saw, I concluded that the hæmorrhage proceeded from the lower opening of the lacerated superior profunda artery. The patient must have lost about fourteen to sixteen ounces of blood, and was very much reduced in consequence. The wound was kept for some little time exposed, light cold water-dressing applied, some restoratives administered, and the utmost quiet enjoined. Upon this occasion, whilst examining the wound, and passing the probe high up anteriorly, I could distinctly detect shot lying upon the front of the thorax, almost touching the lower edge of the clavicle, and at a point about four inches internal to the acromion process of scapula. I attempted to extract them with the dressing forceps; but not easily succeeding, I was deterred by the proximity of the axillary artery from prosecuting the effort, although the ultimate descent of these bodies may very much endanger the artery.

18th.-Patient slept well during the night, and no return of hæmorrhage; the wound also presents a better appearance than I could have expected from the disturbance of yesterday morning. Unfortunately, however, the manipulation has interrupted the process of union, and reproduced the displacement of bones. Pulse 124, small and compressible, with attendant debility, but skin soft and natural; tongue clean, and appetite good; bowels regular, with tapeworm in motion secretions healthy. Extracted twelve shot from the dependent incision. Treatment as before, with diet a little more generous.

20th.-No return of hæemorrhage; strength somewhat im. proved; extracted eight shot. Finding an obscure sense of fluctuation in the posterior wall of axilla, I made another depending opening about its centre, which frome its position will be advantageous for the discharge of matter, or such shot as may descend. No action of bowels to-day. Ordered the following mild aperient draught:-Infusion of senna, an ounce and a half; sulphate of magnesia, three drachms; solution of acetate of ammonia, two drachms; tincture of senna, one drachm. General treatment the same.

21st.- Last night was an anxious one; patient restless and sleepless; suffered much from pain and burning heat in the arm, which was alleviated by exposure, cold sponging, attention to position, and the removal of anything likely to cause pressure or impede the circulation; pulse 104; skin hot; slight thirst, but tongue good, and yesterday's draught has produced a full, natural motion, accompanied by tapeworm. Extracted six shot.

Treatment.-Great care observed in dressing and the position of the arm; cold sponging, and to repeat aperient draught. 22nd. - No return of hæmorrhage, but, since the disturbance and displacement of the bones upon that occasion, there has been great difficulty experienced in keeping the fractured extremities in position, the superior fragment projecting anteriorly and externally to the inferior one, and resisting such means as can now be used with prudence to retain it in place.

24 th.-Passed a rather restless night. No pain in the arm, but a constant burning and tingling sensation in the hand and fingers, although great care is observed to avoid pressure or annoyance by splints or bandages. The aperient has produced one good stool, accompanied with tapeworm; tongue clean skin soft; pulse 104. Extracted nine shot from the opening behind the shoulder.

25 th.-Cast night, at twelve P.M., I was called to the patient in consequence of blood appearing on the arm. This I soon saw issued in great volume from the bottom and inner side of the wound high up in the axilla. From its florid colour, the situation whence it came, as well as the inflnence produced upon it by pressure upon the subclavian, I could have little doubt but that it proceeded from an opening in the axillary artery high up. Although I was unluckily obliged to act without the aid of another surgeon in this case, I at once resolved that the poor fellow should not bleed to death without some effort to save him, and was proceeding, whilst the hospital assistant kept up pressure upon the subclavian, to cut down upon the artery at its bleeding point; but when I reflected upon the great depth of the artery at that situation, the thickened, matted, and disordered condition of the parts, produced by the slow descent of the shot, engorged too, as they now were, with extravasated blood, and, moreover, the mutilation required in this operation, I considered it would be giving the patient a better chance to secure the subclavian as it emerges from under the scalenus anticus. Accordingly, having found, upon the moment of my arrival at the bed-side of the patient, and which, indeed, was my first act, that by plunging the thumb of my left hand into the wound, and forcing it high up into the axilla, between the axillary artery and brachial plexus of nerves in front, and the head of the humerus and neck of the scapula posteriorly, and at the same time placing two of my fingers upon the front of the chest, and two in the axilla, I could thus so compress the artery in the mass of soft parts included between the thumb and finger, and plug up the wound, as to command the hæmorrhage, I caused the hospital assistant to place himself in the same position; and while he thus restrained the flow of blood, I proceeded, by the aid of candle-light, to include the subclavian artery in a ligature.

Having tied the artery in the usual way from above the clavicle, the pulsation which I had previously felt with $\mathrm{my}$ thumb when plunged up towards the clavicle, ceased at once, and the hæmorrhage was completely arrested. Neither was there any pulsation to be felt in the brachial or radial arteries. The wound was then closed by double suture, both ends of the ligature conducted from the depending extremity of the incision, and light water-dressing applied. The patient, who had lost from twelve to fourteen ounces of blood, was in a state of extreme exhaustion, and complained upon the moment of some oppression of breathing. The latter feeling soon subsided. Pulse 154, small and thready. By the careful administration of wine, hot milk, and a very concentrated soup given frequently and in small quantities, he began to rally considerably, and by noon to-day the pulse had fallen to 116 , was fuller in volume, and he expressed himself much stronger.

( $T o$ be continued.)

\section{UNUNITED FRACTURE SUCCESSFULLY} TREATED.

Bx E. COOPER, Esq., Norwich.

A perdSAr of the cases of pseudarthrosis occurring in St. Thomas's Hospital, related in THE LANCET of October 11, brings to my recollection a case of a similar kind which was under my care a few years ago. The ease with which the operation was performed, the short time the case was in hand, and its successful termination, I hope you will consider, entitle an epitome of it to stand recorded in your pages.

J. P-, a commercial traveller, aged about fifty years, was driving into Bedford in his chaise, when an accident occurred, by which the tibia and fibula were fractured about midway between the knee and foot. He was conveyed to a tavern in that city, and was very carefully attended for many weeks by, I believe, the best medical anthority of the place. He became at length alarmed at the probable amount of his tavern bill, and his medical attendant had him removed into the hospital, where he had the advantage of the surgical staff of that institution. Weeks, however, wore away, not the least union took place, and after six months, amputation was proposed. He said he was quite reconciled to the operation, but insisted on leaving the hospital, and having the limb removed at home in this city.

The day after his arrival here, he requested me to examine his leg, and mentioned his readiness to have it removed at my earliest convenience. I removed a slight calico roller; afterwards a long, narrow, pasteboard splint, which went down one side of the leg, passed under the foot, and ascended on the other side almost to the knee. The bones were quite free of each other; no callus thrown ont; the upper fragment of the tibia riding over the lower, and threatening to pierce the integument.

I readily got my patient's consent to try any plan I liked, and in the course of a few days, in the presence of the late Mr. Crosse, I made two incisions, each about two inches long, running into each other, so as to form two sides of a triangle. I dissected back the flap, and with a Hey's saw removed the broken ends of the tibia, put them in contact, placed the limb in a M'Intire's splint, laid down the flap, secured it with one suture, and in two days it had united entirely. I then began to paint over it tincture of iodine daily. The construction of the splint enabled me to get at the wound without disturbing the limb.

$X$ had the satisfaction to find, after a short time, callus abundantly secreted. I placed my patient on crutches at the end of a fortnight, and got him out of doors, carrying the weight of the limb in a sling round his neck.

He improved rapidly. At the end of five or six weeks, I re- 
moved the splint for the first time, and with some anxiety rotated the limb. I found very considerable consolidation had taken place. I replaced the splint until the expiration of three months after the operation, keeping him in good exercise all the time; after which time it was cautiously relinquished, and now he walks, without the least Iameness, by having one sole of his boot a little thicker than the other. Tombland, Norwich, October, 1851.

\section{A fitror}

OF THE PRACTICE OF

\section{MEDICINE AND SURGERY IN THE}

HOSPITALS OF LONDON.

Nulla est alia pro certo noscendi via, nisi quam plurimas et morborum, et dissectionum historias, tum aliorum proprias, collectas habere et inter comparare.-MorgagNi. De Sed. et Caus. Morb., lib. 14. Proomium.

\section{UNIVERSITY COLLEGE HOSPITAL.}

Wound of the Abdomen; Protrusion and Perforation of the Intestine and Mesentery; Recovery.

(Under the care of Mr. ERICHSEN.)

Is speaking of wounds of the abdomen, John Bell observes: "Death from such a wound is a daily and expected occurrence, and therefore it is not marked; but if we find that a man has escaped, are we not to record every such escape? Is it not our duty to set up and marshal in fair array all the possible wounds,-to mark out which are possibly safe and which are absolutely mortal,- to distinguish the various accidents of all the various wounds,-and to try whether, by such observations, we can lessen the danger." (" Principles of Surgery.")

Feeling the justice of these remarks, we have thought it would be of interest to lay before our readers the particulars of the following case of very severe wound of the abdomen that has recently been under Mr. Erichsen's care, and to which we a short time ago cursorily alluded. (THE LANCET, vol. ii., 1851, p. 250.) The following details have been obtained from the notes taken by Mr. Turle, the dresser of the case:-

Julia $\mathbf{S}$ _, a married, healthy-looking woman, of moderate conformation, the mother of eleven children, was admitted, under the care of Mr. Erichsen, at one A.M., on the 27th of June, 1851, having been stabbed in the abdomen, with a long, narrow knife, about an hour previously.

On removing the clothes, which had been transfixed by the instrument, a wound, five-eighths of an inch in length, was observed in the abdominal wall, two inches below the umbilicus, and half an inch to the left of the mesial line. Through this aperture a coil of small intestine, with its mesentery, was seen to protrude, forming a tumour about eight inches in diameter. This coil, which was congested, and of a deep-red colour, appeared to contain about a yard of intestine. On examining this, a wound, oblique in direction, and five-eighths of an inch in length, was found in the most prominent part of the gut. Thin liquid fæeces and flatus were escaping from it. A second wound in the gut, through which flatus and fæces likewise escaped, was found nearly opposite to the first, and about an inch from it. This latter aperture was about half an inch in length, more longitudinal in direction, and less open, in consequence of the eversion of the mucous coat over its edges. In the mesentery, at a distance of two or three inches from its visceral attachment, was observed a cut, about five-eighths of an inch in length.

The house-surgeon, Mr. Lister, thinking it desirable to red uce the protruded unwounded mass of intestine, before attempting to close the wounds in the injured portion, so that the former might not suffer by prolonged exposure and constriction, proceeded to clear away the fxculent matters by which the protruded intestine was besmeared, by pouring water, of about blood heat, over it. An attempt at reduction was then made by the gentle employment of the taxis. This, hawever, it was found im- possible to accomplish, owing to the small size of the wound in the abdominal walls, by which wound a very tight constriction was exercised on the neck of the protrusion. This opening was accordingly cautiously enlarged upwards and inwards, to the extent of about three-fourths of an inch; and thus the greater part of the protrusion was returned with facility.

The knuckle of intestine, upon which the above-deseribed wounds had been inflicted, was now alone protruding, and these were now neatly stitched up by fine needle and silk, great care being taken to include in the stitches little except the peritonæal covering of the gut, and to invert the edges so that the serous surfaces were brought into apposition. The stitches were made close to one another, and the suture was of the continuous kind. After the wounds had thus been closed, the silk was knotted, the ends cut off close to the knots, and the wounded intestine lightly returned.

After the return of the gut, a small quantity of red, watery fluid was observed to escape from the abdomen. The lips of the wound in the abdominal walls were brought together by a couple of sutures through the skin, which were supported by adhesive plaster, and some light water-dressing was laid over the whole. Very little blood had been lost, and the patient was perfectly sensible, though somewhat faint. A dose of opium was administered; she was put to bed, directed to be kept quiet, and restricted to barley-water and ice: one grain of solid opium was ordered every third hour.

So far the case had been entirely conducted by Mr. Lister, to whose skill and judgment, both then and after, much of its successful issue may be attributed.

At one P.M., about thirteen hours after the accident, the report states that the patient felt easy, and had had some sleep. The pulse was 92, full and compressible. At half-past eleven P.M., the pulse was 76 , compressible and moderately full; no pain complained of but a dragging sensation in the right hypochondrium. The opium pills were ordered to be continued, and the urine to be drawn off with a catheter twice in the twenty-four hours.

First day after adınission.-Ten A.M.: There are now distinct symptoms of peritonitis-viz., considerable tenderness over the whole of the abdomen, with occasional acute pain, which is increased on inspiration; dorsal decubitus; legs drawn up, and some tympanitis; tongue moist, and but slightly coated with a white fur; pulse still 76 , compressible, and moderately full. The opium was ordered to be continued, and twentyfour leeches to be applied to the abdomen, followed by hot poultices.

These means afforded her much relief, and at twelve o'clock the same night, about forty-eight hours after the infliction of the injury, the symptoms of peritonitis had considerably subsided, and the opium had procured her some refreshing sleep. Towards morning, however, being the second day, the symptoms of peritonitis increased considerably in intensity; there was much pain and tenderness, principally in the right side of the abdomen, with tympanitic distention of the whole of that cavity; the tongue had become dry and slightly brown, but the pulse did not exceed 78, though it was somewhat less compressible than before. There was anxiety of countenance, and much thirst; respirations, thoracic, and 38 in the minute. Twenty-four leeches were again applied to the abdomen, and were followed by poultices and fomentations. These means relieved the pain considerably; but the other symptoms continued much as before, except that the pulse rose to 90 after the application of the leeches. At nine A.M. of the same day the patient was seen by Mr. Erichsen, who ordered the opium pills to be omitted, and a pill composed of two grains of calomel and a quarter of a grain of opium to be taken every hour. At one P.M. the pulse had fallen to 84 , and was softer; there was less anxiety of countenance, and the pain was less severe. The calomel pills were now ordered to be taken every second hour. At seven P.M., the symptoms were still further mitigated; the skin and tongue had become moist, and the patient expressed herself as feeling much better, there being less soreness and no pain in breathing.

Third day after the injury.-The patient has passed a good night; her appearance is better, there being less anxiety of countenance; pulse 90 , small and soft; respirations 26 ; the abdomen is much less tender and tympanitic, but there is some dulness in the left flank, and the skin and tongue are again dry. Ordered to continue the pills every third hour, with the addition of two grains of James's powder to each. In the evening the pills were discontinued al together, as the gums had become sore. As the bowels had not been relieved since the injury, (nearly four days,) and as there appeared to be some accumulation in the left colon, it was thought that an enema might be given with advantage. Accordingly, at half-past ten P.M., a 